\title{
Leadership for Professional Learning towards Educational Equity: A Systematic Literature Review
}

\author{
Philip E. Poekert ${ }^{\mathrm{a}}$, Sue Swaffield ${ }^{\mathrm{b}}$, Ema K. Demir ${ }^{\mathrm{b}}$, Sage A. Wright ${ }^{\mathrm{a}}$. \\ ${ }^{a}$ University of Florida, United States ${ }^{b}$ University of Cambridge, United Kingdom.
}

Corresponding Author: Sue Swaffield, University of Cambridge, Faculty of Education 184 Hills Road, Cambridge, CB2 8PQ, UK.

ses42@cam.ac.uk

\begin{abstract}
This systematic review of recent research explored the uncharted intersection of literature on educational leadership, professional learning, and educational equity. It investigated leadership approaches to shaping the professional development and ongoing learning of educators that supports more equitable outcomes for students. The underlying motivation for the work is our concern for the educational experiences and achievements of marginalised students, and for professional learning to address these inequalities. Guided by the Preferred Reporting Items for Systematic Reviews and Meta-Analyses (PRISMA) Statement, and iterative selection of literature based on relevance and quality judged by weight of evidence assessments, we identified 41 empirical items for detailed analysis. The outcome was five themes: Critical framing of social justice issues; Dialogue and enquiry; Learning and identity development; Context, resources, and motivations; Normalising inclusion and shared leadership. A further six articles informed a conceptual framework linking professional learning and outcomes that developed existing models. Critique of linear conceptualisations of learning, and affinity with the values and philosophy of the process model of education championed by Lawrence Stenhouse, prompted proposing the themes as nascent principles. These require further research, yet they have immediate practical utility for educational leaders and teachers working in pursuit of educational equity.
\end{abstract}

Keywords: Professional Learning; Leadership; Educational Equity; Review of Research 


\section{Introduction}

A significant consensus had been achieved on the characteristics of effective professional learning by the advent of the new millennium (e.g. Desimone et al., 2002). Yet, since then, teachers have continued to report ineffective or irrelevant professional learning opportunities (Darling-Hammond et al., 2009). Worse still, the achievement gaps and education debts between historically marginalised groups of students and their more affluent peers persist (Ladson-Billings, 2006; Schleicher, 2019). Within this gap between what we know and what we do (Pfeffer et al., 2000), this article surveys recent literature connecting leadership with professional development and learning, examining research that addresses issues of educational inequity in schools. This effort is undertaken to identify how leaders of professional learning can employ particular approaches in the ongoing support of educators that lead to more equitable outcomes for students.

For this article, educational equity is taken to mean a state in which dimensions of privilege and oppression (e.g., race, ethnicity, socioeconomic status, gender, sexual orientation, religion) are not predictive of or correlated with educational outcomes, broadly defined, in any significant way, and where all learners are able to participate fully in quality learning experiences. Leadership is understood as the exercise of influence and can be undertaken formally or informally by anyone. Following the reasoning of Opfer and Pedder (2011), we deliberately use the term professional learning to avoid focus on specific professional development programmes, activities, or individuals at the expense of context and the situatedness of learning which includes continuous practices of interaction and reflection. The authors acknowledge that they are privileged by virtue of race but offer this scholarship as allies (Patton \& Bondi, 2015) working for social justice for historically marginalised groups.

This literature review aims to address three research questions (RQs):

1. What models are suggested by recent literature review and conceptual articles that include consideration of leadership, professional learning and educational equity?

2. How can leadership advance professional learning toward educational equity?

3. What are the challenges and proposed solutions concerning leadership for professional learning commonly identified in the literature?

\section{Method}

This review is guided by the Preferred Reporting Items for Systematic Reviews and Meta-Analyses (PRISMA) Statement (Moher et al., 2009). The PRISMA Statement consists of a 27-item checklist and a four-phase flow diagram (see Figure 1 below) that sets out how to identify, select, and critically appraise relevant research, and how to collect and analyse data from the studies included in the review. It also provides the format for presenting information, which has guided this article. Further, this review follows the extension of the PRISMA statement (Welch et al., 2012) for the development of equity-focused systematic reviews. The PRISMA approach was chosen to ensure rigour and minimise bias in the review process. Quality and relevance appraisal was guided by the Weight of Evidence (WoE) framework developed by Gough (2007), as explained in further detail below.

\section{Identifying search terms}

This review attempts to map the emerging field of research that addresses the increasingly urgent issue of promoting educational equity and social justice through 
leadership for professional learning. Synonyms to the concepts were identified using an online thesaurus. Discussion of these synonyms led to the identification of the following search terms:

- Leadership, educational leaders, school leaders, school leadership, teacher leaders

- Professional learning, professional development, career development

- Equity, egalitarian, equal, equality, equitable, fair, fairness, inegalitarian, inequity, inequality, injustice, just, justice, justness, unequal, unjust.

\section{Search strategy}

Step 1: A Boolean search phrase was used to combine the search terms and identify relevant research outputs. An initial full-text search in electronic databases was conducted within Scopus and Web of Science in November 2019. These databases were chosen according to their relevance to the topic: Scopus (Social Sciences), and Web of Science (Multidisciplinary Sciences, Education, Educational Research, Education Scientific Disciplines, Educational Psychology). Synonyms were made interchangeable and could appear anywhere in the text. This search generated 488 items of which 27 were review and conceptual articles. Of these, 20 were considered relevant for answering RQ1 and underwent an in-depth review by the authors. A subset of six articles was employed in developing a conceptual framework summarised in this article because they spoke to the constructs addressed within it.

Step 2: In February 2020, a second search was carried out within Scopus and Web of Science to generate empirical research with a more explicit focus on leadership for professional learning towards equity. This time, search outputs were limited to subject terms, meaning words had to appear as keywords, in the title, or in the abstract of identified items. To avoid limitations of using pre-determined search terms and controlled vocabulary (Brunton et al., 2012), additional hand-searches were carried out for the period 2009 - 2020 in the key journal Professional Development in Education Journal (PDiE) and searching the reference list of the bibliographical review by Hallinger and Kulophas (2020). The process used to complete this second search, and the results of the search, now follow.

\section{Eligibility criteria}

Publication type was limited to peer-reviewed, empirical studies. Items related to the professional learning of in-service K-12 and early years educators were included. Accordingly, items related to post-secondary or higher education were excluded as were pre-service or student teachers. The time frame of the last 10 years was set to generate recent empirical research outputs that could tell us about the direction and emerging issues of future research. The inclusion and exclusion criteria are displayed in Table 1 below. 
Table 1. Inclusion and exclusion criteria.

\begin{tabular}{l|l}
\hline Inclusion criteria & Exclusion criteria \\
\hline Population & $\underline{\text { Population }}$ \\
In-service teachers & Pre-service teachers \\
K-12 teachers & Teacher educators \\
School leaders & Student teachers \\
Principals & $\underline{\text { Context }}$ \\
School administrators & Post-secondary education \\
(District) policy makers & Higher education \\
Context & Vocational education \\
K-12 education & College education \\
Early years education & $\underline{\text { Item type }}$ \\
Primary school & Reviews \\
Elementary school & Conceptual articles \\
Middle school & Conference papers \\
Secondary school & Not in English \\
Upper secondary school & No full text available \\
Item type & \\
Empirical & \\
Peer reviewed & \\
\hline
\end{tabular}

\section{Results}

\section{Study selection}

The numbers of items identified per database were Scopus (36), and Web of Science (80). Hand-searches in PDiE and the reference list of Hallinger and Kulophas (2020) review article generated 50 items, which led to 166 identified items in total. The removal of duplicates (16) and non-empirical items (19), and application of inclusion/exclusion criteria (11 removed), generated 120 items.

Each author read all 120 abstracts, checking for a clear focus on equity/social justice. The authors' few discrepancies regarding relevance were resolved through discussion until consensus was reached. This process led to the removal of 77 items. Two articles were removed on the basis of quality (1) and relevance (1) appraisal, leaving a total of 41 empirical items to be included in the review for RQ2 and RQ3. The selection process is outlined in the flow-chart below (Figure 1). 
Figure 1. Flow-chart of study selection.

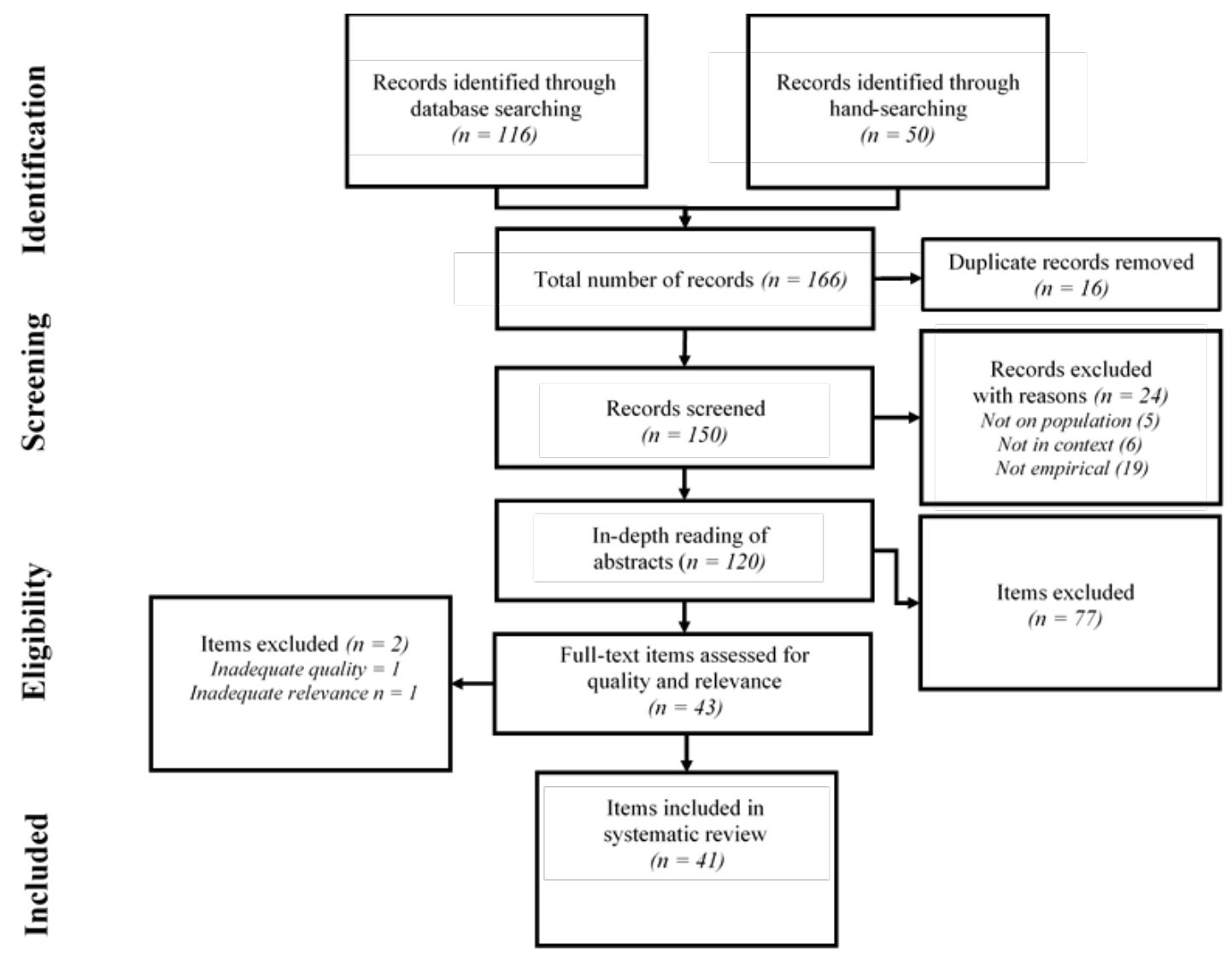

Note: Adapted from The PRISMA

Statement (Moher et al. 2009, p.3)

\section{Descriptive statistics of included items}

All but one of the included items in this review are journal articles (one is a book chapter). Per PRISMA guidance, the following surface characteristics were gathered for each empirical item: population, context, location, and research method. 
Figure 2. Descriptive statistics of included items.

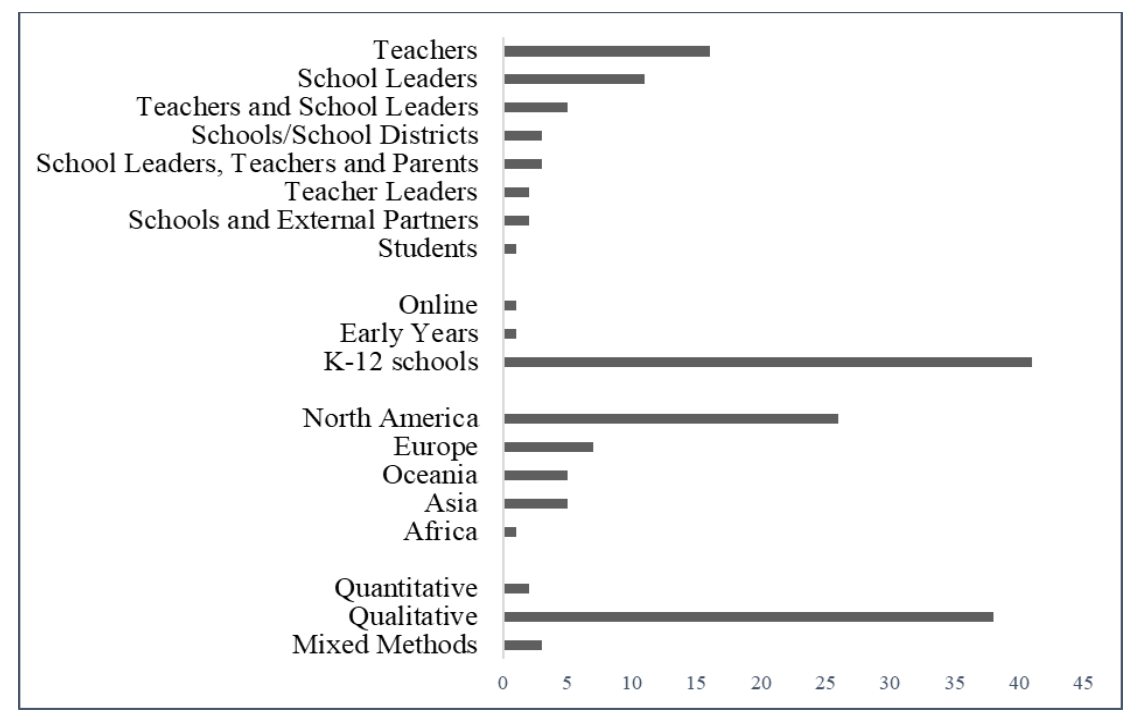

As shown in Figure 2, 34 of the studies' participants were either teachers or school leaders, or both teachers and school leaders. Eight studies took a wider approach, looking at schools/school districts or include parents and external partners. Only one study had students as the focus of analysis. Given the eligibility criteria for context, most studies had been carried out in a K-12 school setting, while one study took place in an early childhood setting and one in an online environment.

The qualitative studies overwhelmingly outweigh the number of quantitative studies, while a small number of studies employ a mixed methods approach. Sample sizes range from only two participants in some of the qualitative studies to almost a thousand in one of the quantitative studies.

\section{Risks of bias}

Most of the studies were carried out in North America, and of these 96 percent originate in the US. A smaller number of studies was carried out in Europe and Asia, while only one took place in Africa. This represents a risk of geographical and cultural bias. It can also be interpreted as a result of the limitation to research outputs in English, which may have led to an overrepresentation of studies from English-speaking countries. It also can be a manifestation of the relative dominance of English-speaking countries in terms of research outputs, rather than a result of the linguistic limitation per se. However, this review does present examples from a number of national contexts.

\section{Quality and relevance appraisal}

All empirical articles were assessed according to the Weight of Evidence (WoE) framework for the appraisal of the quality and relevance of evidence developed by Gough (2007). This process guided the authors' identification of key pieces in this review.

The Weight of Evidence framework employs three dimensions: Evidence A is a non review-specific assessment of the coherence and integrity of the evidence in its own terms; Evidence B assesses the appropriateness of that form of evidence for answering the review question; and Evidence $\mathrm{C}$ is a review-specific judgement about the relevance of the focus of the evidence for answering the review questions. Each is scored on a scale of 0-3 considering the extent to which the criteria were met: $0=$ not at all met, $1=$ 
met to some extent, 2 = mostly met, 3 = fully met. An overall rating: high, mid or low, is then established for each item based on its average score, WoE D.

After separate scoring for WoE A, B and C, pairs of authors discussed discrepancies and arrived at a joint WoE D. Special attention was paid to Evidence C for each article, as it assessed the relevance of the focus of the evidence for the RQs of this review. As shown in Table 2, which gives the rankings of articles according to WoE $\mathrm{C}$ and D, a large majority of included items scored high (18) or mid (20) while only three (3) scored low indicating that the overall quality, methodological rigour and relevance of included items was generally high.

Table 2. Weight of Evidence C and D.

\begin{tabular}{|c|c|c|c|c|c|}
\hline Senior Leadership Focus & WoE C & WoE D & Teacher Leadership Focus & WoE C & WoE D \\
\hline Braaten et a. (2017) & 3 & 3 (high) & Brown \& Crippen (2017) & 3 & 2.67 (high) \\
\hline Galloway \& Ishimaru (2019) & 3 & 3 (high) & Deckman (2017) & 3 & 2.67 (high) \\
\hline Gannon-Slater et al. (2017) & 3 & 3 (high) & Jacobs et al. (2014) & 3 & 2.67 (high) \\
\hline Hallinger \& Liu (2016) & 3 & 3 (high) & Szelei et al. (2019) & 3 & 2.33 (mid) \\
\hline Kose (2009) & 3 & 3 (high) & Ezzani (2019) & 2 & 2.33 (mid) \\
\hline Miled (2019) & 3 & 3 (high) & Nicholson \& Kroll (2015) & 2 & 2.33 (mid) \\
\hline Park (2018) & 3 & 3 (high) & Hynds \& McDonald (2010) & 2 & 2 (mid) \\
\hline Reed \& Swaminathan (2016) & 3 & 2.67 (high) & Bryan (2011) & 2 & 1.67 (mid) \\
\hline Anthony \& Hunter (2017) & 2 & 2.67 (high) & Yoon (2016) & 2 & 1.67 (mid) \\
\hline Hynds (2010) & 2 & 2.67 (high) & Ali (2014) & 1 & 1.67 (mid) \\
\hline Kohli (2019) & 2 & 2.67 (high) & & & \\
\hline Mansfield (2014) & 2 & 2.67 (high) & & & \\
\hline Mistry \& Sood (2015) & 2 & 2.67 (high) & & & \\
\hline Theoharis \& O'Toole (2011) & 2 & 2.67 (high) & & & \\
\hline Gomez-Hurtado et al. (2018) & 1 & 2.67 (high) & & & \\
\hline Bristol (2015) & 3 & 2.33 (mid) & & & \\
\hline Ashadi \& Rice (2016) & 2 & 2 (mid) & & & \\
\hline Fwu \& Wang (2012) & 2 & 2 (mid) & & & \\
\hline Nehring \& Fitzsimons (2011) & 2 & 2 (mid) & & & \\
\hline Payne \& Smith (2018) & 2 & 2 (mid) & & & \\
\hline Scanlan $(2010)$ & 2 & 2 (mid) & & & \\
\hline Carpenter et al. (2017) & 1 & 2 (mid) & & & \\
\hline DeMatthews \& Izquierdo (2016) & 1 & 2 (mid) & & & \\
\hline Hajisoteriou et al. (2018) & 1 & 2 (mid) & & & \\
\hline Lazar \& Reich (2016) & 2 & 1.67 (mid) & & & \\
\hline Martinez et al. (2019) & 1 & 1.67 (mid) & & & \\
\hline Murakami \& Tornsen (2017) & 1 & 1.67 (mid) & & & \\
\hline Stosich (2017) & 1 & 1.67 (mid) & & & \\
\hline Brinia (2012) & 1 & 1.33 (low) & & & \\
\hline Bristol \& Ponte (2013) & 1 & 1.33 (low) & & & \\
\hline Blank (2015) & 1 & 1 (low) & & & \\
\hline
\end{tabular}




\section{Identifying themes}

Through the reading of all items by all four authors, two domains of literature emerged: one focusing on senior leadership, both school and district, and the other focusing on teacher leadership, both formal and informal. Thirty-one papers were identified as taking a senior leadership view, while 10 papers were from the perspective of teacher leaders. Pairs of authors focused on the respective strands. Recording key points and ideas for papers within each domain, the authors independently proposed analytical themes, then discussed them in pairs to arrive at a set of themes for each domain. These were finally synthesised into the following themes identified as providing answers to RQ2 and RQ3:

1. Critical framing of issues toward social justice

2. Dialogue and enquiry

3. Learning and identity development

4. Context, resources, and motivations

5. Normalising inclusion and shared leadership

In the following four sections we first present the conceptual framework developed in response to RQ1, then a thematic analysis of empirical studies addressing RQ2 and $\mathrm{RQ} 3$, leading to the discussion and conclusion.

\section{A conceptual framework of professional learning}

Surveying the conceptual literature and literature reviews linking leadership and professional learning published in the last 10 years yielded few contributions to the consensus view that had already surfaced by the early 2000s on the characteristics of effective professional learning: (a) content focus, (b) active learning, (c) coherence, (d) collective participation, and (e) duration (Desimone, 2002). Certainly, publications reinforced prior work, illustrating and replicating common themes. What has emerged, however, is a metasynthetic view of the literature that provides a refined framework of professional learning. The framework synthesises models proposed in conceptual articles by Coldwell and Simkins (2011) on professional learning and Hallinger (2018) on leadership contexts, and has been enhanced by contributions from four additional conceptual and review pieces attributed below. 
Figure 3. A conceptual framework of professional learning.

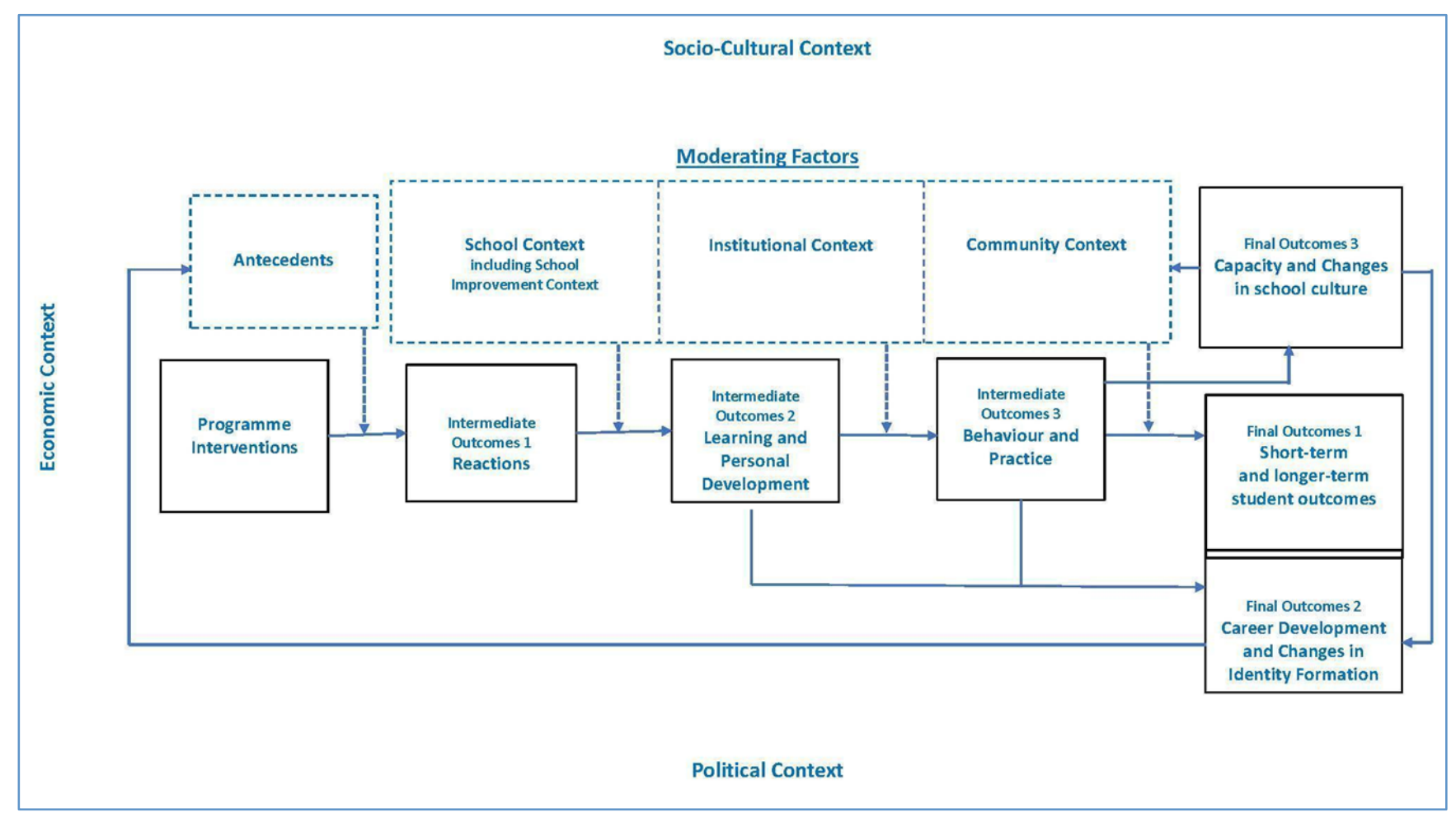

The framework is organised as a linear progression from left to right with arrows indicating how one construct influences another, acknowledging that cyclical relationships exist between many of the constructs, resulting in feedback loops. These constructs, and the outcomes they influence, operate within and are moderated by the context of the school, the institution, and the community, as well as the larger economic, political, and socio-cultural context. More detail on each area of the conceptual framework follows below.

\section{Programme interventions}

The construct of programme interventions describes professional learning activities themselves. Clearly, activities vary in their format, content, and duration. Those activities which adhere to the characteristics outlined by Desimone and colleagues (2002) are regarded as more effective because they may have a greater likelihood of achieving the desired outcomes of improved teacher knowledge and practice, and student learning.

\section{Antecedents}

Participant motivations and expectations influence how educators approach professional learning and how their approach, in turn, influences their experience (Castanheira, 2016). Coldwell and Simkins (2011) illustrated this phenomenon by pointing to a study of a leadership development programme in which the participants' interest in promotion affected the extent and quality of participants' engagement, presumably influencing the ultimate outcomes. Hallinger $(2018$, p. 7) referred to this as a 'person-specific context', encapsulating how job knowledge, skills, attitudes, and experiences 'act as a prism through which information, problems, opportunities, and situations are filtered and 
interpreted'.

Sun (2015) added teacher efficacy as a variable that influences professional learning outcomes, capturing the influence of belief systems. Optimistic beliefs about one's efficacy positively influence educators' engagement in professional learning activities and the outcomes of those efforts. Finally, Cruz-Gonzalez and colleagues (2019) contributed professional identity as an influencer, noting the construction of identity is a combination of internal experiences and the surrounding context. The larger context is discussed below.

\section{Moderating factors}

Moderating factors capture the influences of organisational contexts independently from the antecedents. Hallinger $(2018$, p. 7$)$ called these factors the 'widely shared context', referring to the features of the broader environment in which professional learning operates, separating out three categories: the school context, the institutional context, and the community context.

School Context. The school context refers to characteristics of the school environment, including organisational structure and culture, time for professional learning, and support available to participants (e.g., coaching; Coldwell \& Simkins, 2011). Hallinger (2018) added 'school improvement context' to refer to the ways a school's historical context influences its improvement trajectory. According to Hallinger (2018, p. 15), the 'trajectory defines the nature of a principal's leadership challenge', which moderates the experience of professional learning, and influences its outcomes.

Institutional Context. The institutional context includes the education system in which a school operates, like a district, or national system. Hallinger (2018) pointed to empirical research by Lee and Hallinger (2012), which found that institutional structures influence the role definition and behaviour of principals, with principals in more structured systems allocating less time for administration. The degree of system centralisation, including accountability systems, also has a great influence on the role and practice of school leaders, and thus shapes the context (Hallinger, 2018).

Community Context. The community context is the local environment immediately surrounding an individual school. This context is shaped by the socioeconomic status of the student population, family involvement in school activities, the urban or rural character of the surrounding areas, and the presence of conflict in the community (Hallinger, 2018). This context can vary widely and have profound influences on leadership and professional learning.

\section{Broader context}

Hallinger (2018) captured macro-level features in three categories: socio-cultural, economic, and political:

Socio-cultural context. Leadership is value driven, and the value sets and norms for behaviours vary geographically. Socio-cultural values fundamentally influence perceptions of what constitutes effective leadership. For example, the Lee and Hallinger (2012) study is referenced to note that principals from less hierarchically organised societies may allocate more time for instructional leadership and spend more time interacting with families and the school community.

Economic Context. Economics fundamentally shape conditions in schools, including teacher qualifications, class size, per-pupil expenditures, parental education and involvement, school resources, and more. Furthermore, as societies develop economically, the role of educators is more professionalised. For example, Lee and 
Hallinger (2012, pp. 12-13) documented that 'principals from societies with higher GDP tended to spend more time on the job', influencing the amount of time spent on instructional leadership.

Political Context. Education policies reflect the prevailing power structures and relationships within a society, thus influencing the practice of leadership for professional learning through the beliefs, attitudes, and practices of educators. Furthermore, the political context determines the national goals of education, which in turn set expectations for which outcomes are of the highest priority. For example, Fry and $\mathrm{Bi}$ (2013) noted that in Thailand, three goals are at the heart of national education policy: the capability to apply knowledge; student morality; and student happiness. Setting such goals politically shapes the context in which leadership for professional learning is undertaken.

\section{Intermediate outcomes}

Intermediate outcomes are 'outcomes of CPD [continuing professional development] that are conceived to be pre-conditions for the achievement of the final outcomes, particularly learning and changes in participant behaviour' (Coldwell \& Simkins, 2011, p. 147). These include (1) participants' reactions to professional learning, influenced by antecedents (i.e., participants' expectations and motivations, efficacy, and identity). In turn, these reactions influence (2) the learning and personal development of educators, an outcome which itself is influenced by the moderating context at the school, institutional, and community levels as well as the broader context. As educators learn and develop, this influences (3) behaviour and practice in the school and classroom. Changes in practice are again moderated by contextual factors.

\section{Final outcomes}

Final outcomes are 'the intended effects of the CPD activities, primarily relating to effects on organisations, teachers, and students' (Coldwell \& Simkins, 2011, p. 147). Of greatest relevance are (1) student outcomes, both short-term, including grades, and longer-term outcomes, including standardised assessments and quality of life outcomes. Final outcomes for individual educators (2) include advancing career development (Coldwell \& Simkins, 2011) as well as changes in identity formation (Cruz-González et al., 2019; García-Martínez \& Tadeu, 2018). Final outcomes at the school level (3) include improvements in the capacity of individuals, teams, and the overall school systems and processes (Coldwell \& Simkins, 2011), as well as changes in school culture (Sun, 2015). These influences on participants and schools give rise to larger feedback loops that influence the antecedents, moderating factors, and broader context in which future professional learning activities are implemented.

With this framework built on the conceptual and review literature as background, the following section explores the findings from our second search focused on the empirical literature that addresses issues of educational equity.

\section{Leadership practices, challenges, and solutions}

Drawing on both senior and teacher leadership focused empirical studies, this section addresses RQ2 - investigating the ways leadership can advance professional learning toward educational equity, and RQ3 - exploring the challenges and solutions offered in the literature. It is structured by the five themes that emerged through analysis; within each theme senior leadership literature is considered first followed by teacher leadership literature. Studies tended to focus one on form of inequality (e.g., racism); many were 
relevant to more than one theme; and studies with a higher WoE tend to offer evidence for multiple themes.

\section{Critical framing of issues toward social justice}

Framing is the first theme we address since it represents the way an issue is viewed and interpreted, both individually and collectively and thus shapes leadership actions; it also infuses the other themes.

Galloway and Ishimaru (2019; high WoE) draw on a framework of organisational leadership for equity they published in 2017 in which framing is a prominent feature. They describe framing as a driver of equitable leadership practices and as an analytical lens for exploring how school principals prioritised developing staff capacity to address disparities for students in minority groups. Notably the principals worked to establish "equity" framing of disparities and solutions in relation to race and racism' (Galloway \& Ishimaru, 2019, p. 14). Nevertheless, deficit-based orientations remained, overshadowing systemic and historic understandings of inequitable student outcomes. Other researchers refer to the deficit framing of social justice in oppositional terms, contrasting it with a frame of disparity (Park, 2018) or the celebration of difference (Gomez-Hurtado et al., 2018), and frame diversity as a strength rather than a weakness (Theoharis \& O'Toole, 2011).

Another high WoE item by Braaten and colleagues (2017) spoke to critical framing in a study that traced the translation of data-centric reforms into practice in US secondary schools. District leaders sought manageability and coherence by 'bundling' together multiple initiatives, all measured by considering disparity between students' interim assessments and later test scores. This framing affected how school principals mediated the reforms and in turn affected teachers' experiences and practice, all with consequences for students' equitable access to learning. The research raised concerns that the narrow framing of school improvement seriously reduced the quality of students' learning opportunities.

\section{Critical framing in the teacher-focused literature}

For teachers, framing creates opportunities to engage in critical reflection on the dynamic influences of class, culture, and politics, and the ways forms of oppression intersect (Nicholson \& Kroll, 2015; mid WoE) and compete within educational contexts. Addressing these issues directly and intentionally within professional development programmes equips teachers to enact curricular and pedagogical changes that will disrupt structural inequities (Jacobs et al., 2014; high WoE) and promote socially just outcomes for students.

Critically framing leadership development with an equity mindset can help to ensure that teachers develop a deeper awareness of their students and their cultural diversity while disrupting homogenised perspectives that may otherwise have been reinforced (Deckman, 2017; high WoE; Szelei et al., 2019; mid WoE). However, Deckman (2017) cautions school and teacher leaders to be sensitive to novice educators, who may equate the critical reflection process with being seen as less competent than their peers.

Brown and Crippen (2017; high WoE) recommend that professional development programmes pair critical reflection with a guided critical examination of intersecting inequities affecting students from marginalised populations. This open and authentic dialogue (Jacobs et al., 2014) challenges deficit thinking and raises sociocultural awareness and calls for educators to commit to enacting change 
(Nicholson \& Kroll, 2015). In Ezzani (2019; mid WoE) teacher leaders collaboratively examined literacy assessments with a cultural gaze and were able to identify student populations not benefiting from the current reading curriculum.

Studies with lower WoE scores also contribute to the critical framing theme. A professional learning programme for teacher leaders in Pakistan (Ali, 2014) directed explicit attention to issues of gender inequity, helping participants to overcome beliefs contributing to such inequities in schools. Additionally, a US ethnographic study (Yoon, 2016) explored ways in which white, middle class ideology can inform or derail collaborative efforts through the act of storytelling in professional learning contexts. Raising awareness of members' positionalities through reflection, reframing stories, telling counter-narratives, and examining institutional limitations and needs can promote more equitable perspectives about students and parents from marginalised populations.

\section{Dialogue and enquiry}

Dialogue and engaging in enquiry emerged as intertwined activities essential to leadership for professional learning towards social justice. In one of the key empirical articles focusing on dialogue and enquiry Bristol (2015; mid WoE) adopts the term 'teacher talk' from Hardy (2010), using it to refer to dialogue among educational professionals at all levels. A case study of rural Australian primary schools revealed 'the enormous potential of purposeful teacher talk in the creation of more inclusive educational practices' (Bristol, 2015, p. 817). Teacher talk was used as a source of data, and to challenge established cultural practices and attitudes. Inclusive action was promoted through dialogue and reflection in trustful 'designed communicative spaces'. The school principals facilitated dialogue characterised by shared responsibility, equity of voice, critical listening, curiosity, affirmation, and the challenging of implicit assumptions.

Similarly, the leadership of data dialogue was studied by Gannon-Slater and colleagues (2017; high WoE). They referred to 'data talk' as 'the structure and content of team conversations about interim student performance data' (p. 361). Through their US study of elementary school grade-level teams, they emphasised leaders shaping the culture, focus and nature of data dialogue in professional learning communities (PLCs), the prioritisation of equity focused teacher enquiry, and the use of enquiry routines. The leadership of data dialogue, the use of routines, the integration of enquiry and data all also feature in Galloway and Ishimaru's (2019) depiction of an enquiry culture focused on equity. Hynds (2010; high WoE) examined social justice reform from the perspectives of both the majority and minority stakeholder groups in New Zealand. The study revealed resistance as a developmental process as well as a construct, stressing that leaders must involve everyone in collective enquiry and sustained dialogue facilitated by inclusive protocols and principles.

Finally, Park's (2018; high WoE) analysis of dialogue, revealed approaches that have the potential to foster more equity orientated thinking and actions. Key 'data conversation moves' observed in a school's PLCs and more informal settings were data triangulation, reframing deficit thinking to building on student assets, pedagogical linking, and student-centred positioning, extending, and confirming/disconfirming.

Other studies (mostly with lower WoE) also speak to leadership for professional learning towards social justice through PLCs and enquiry groups (Lazar \& Reich, 2016), action research (Bristol \& Ponte, 2013), and networks (Gomez-Hurtado et al., 2018; Kohli, 2019; high WoE). Additionally, Fwu and Wang's (2012) study reminds us of the importance of equity and diversity in school-university collaborations. 


\section{Dialogue and enquiry in the teacher-focused literature}

Teachers benefit from programmes featuring socially constructivist approaches like engagement in online forums that facilitate sustained exchanges to disrupt patterns of inequity (Nicholson \& Kroll, 2015), and that foster the reframing of racial narratives (Deckman, 2017). Additionally, developing an enquiry stance (Cochran-Lytle \& Smith, 2009) and engaging in reflection (Nicholson \& Kroll, 2015) can be critical components for teacher leaders to work with complexity and uncertainty, offering mental space to reflect upon praxis. The 2015 study's leadership development offers support that deepens dialogic connections about contextually-based inequities and the need to disrupt them.

Ezzani recommends 'data-informed decision-making' (2019, p. 4), utilising both qualitative and quantitative information to drive professional development efforts toward more equitable outcomes for marginalized students. Leadership programmes' enquiries should be aligned with the issues and needs of everyday life that are contextualised within the school (Szelei et al., 2019). This incisive approach is echoed by Bryan's (2011; mid WoE) observation that programmes focusing on procedural, bottom-line issues would achieve only partial reform; programmes must focus on teacher attitudes for fundamental changes to take place.

\section{Learning and identity development}

Several studies with a high WoE point to the key role of senior leadership for facilitating social identity development of teachers by encouraging self-reflection. Galloway and Ishimaru (2019) call for school leadership that provide routines for dialogue and self-reflection that can challenge biases and reveal racial assumptions and issues of power. Kose (2009) suggests that principals need to cater for two interrelated types of professional development: subject matter expertise and social identity development. Access to subject matter expertise provides necessary scaffolding for those with less subject expertise as well as support for social identity development, a process that creates an on-going learning cycle that feeds back into both.

Some studies argue the benefit of identity development in the early stages of a teacher's career. Kohli (2019) calls for culturally reflective and responsive teacher education that prepares teachers for the socio-political realities of schooling. Explicitly, this involves developing teachers' racial literacy through offering access to critical theory and creating racial affinity spaces for teachers of marginalised groups. Early career teachers can be supported by school leaders and teacher mentors who encourage self-reflection, personal growth, and awareness of issues of social justice (Lazar \& Reich, 2016; mid WoE).

Carpenter and colleagues (2017; mid WoE) suggest that even though senior leaders may be passionate about working towards equitable outcomes, they tend to take an altruistic rather than ally position towards marginalised students.

\section{Learning and identity development in the teacher-focused literature}

Several articles with a high WoE advocate for identity development through critical reflection to better understand the ways in which teachers' socio-political positionalities (Jacobs et al., 2014) inform beliefs about learning (Brown \& Crippen, 2017). In leadership programs seeking to engage novice teachers, critical reflection also can be articulated 'through the lens of identity' (Deckman, 2017, p. 26). Offering teachers structured opportunities to deepen self-awareness while promoting an equitable mindset 
can help educators develop the resiliency to sustain their social justice agendas (Nicholson \& Kroll, 2015).

Relationship-building, both among educators and between teachers and students, drew repeated mention for its ability to catalyse authentic inclusivity and cultural responsiveness in curriculum planning and pedagogy (Brown \& Crippen, 2017), to represent students and their lived experiences (Jacobs et al., 2014). When teachers participate in leadership development that maintains a critical focus on social justice, they can acquire the skills to empower and amplify student voice, rather than reinforcing the structural inequities that have long marginalised students on the basis of ability, race, language, or culture (Szelei et al., 2019).

\section{Context, resources, and motivations}

From a senior leadership perspective, the appreciation and understanding of context, the deliberate use of resources, and tapping into the educators' motivations stood out as crucial to equity work.

The importance of context is manifested by Reed and Swaminathan's (2016) call for 'contextually responsive leadership'. School leaders have been encouraged to use data to inform policy and practice and, more recently, equity work (Galloway \& Ishimaru, 2019). Similarly educational leaders are exhorted to follow research-based practices, while being alert to the 'inescapable, subjective element of best-practice' (Reed \& Swaminathan, 2016, p. 1097).

Other high WoE studies also point to the danger in culturally-blind use of best practice and performance data to inform teaching. Without a culture of enquiry to 'surface and redress the problematic and deeply-rooted structures and practices that maintain outcome disparities for minoritised groups' (Galloway \& Ishimaru, 2019, p. 17) opportunities to capitalise on student-generated ideas, foster sense-making and pursue meaningful and equitable learning outcomes will be missed (Braaten et al., 2017; Gannon-Slater et al., 2017; Park, 2018).

Along the same line of argument we find studies with mid or low WoE that show how performance grouping of students will fuel disadvantage and contribute to marginalisation of students (Anthony \& Hunter, 2017), and how the use of high stakes testing and accountability contributes to and reinforces disadvantage (Ashadi \& Rice, 2016; Carpenter et al., 2017). High quality teachers are more likely to be allocated to year groups that will undergo high stakes tests, which leads to unequal allocation of resources within the school. Moreover, these teachers are also given more professional development opportunities (Ashadi \& Rice, 2016).

Theoharis and O'Toole (2011) suggest that school leadership take a more holistic approach to resources within the school. An often neglected resource that can inform leadership and professional development is listening to student voice (Hajisoteriou et al., 2018; Mansfield, 2014). 'Too often, youth - especially those historically marginalised due to race/ethnicity, gender, and socioeconomic status - are the subject of policies rather than actors in shaping policy' (Mansfield, 2014, p. 398). Becoming aware of the contextual complexities of students, including how their school is situated in the larger community and political context is therefore crucial to inform leadership (Mansfield, 2014).

Finally, a number of articles point to the deliberate use of 'external resources' to promote social justice. These include teacher recruitment (DeMatthews \& Izquierdo, 2016), as well as collaboration with the wider community (Blank, 2015), early childhood educators (Mistry \& Sood, 2015), and private schools (Scanlan, 2010). 
Context, resources, and motivations in the teacher-focused literature

In articles ranking both high and low on the WoE scale, teacher development programmes appear to achieve more equitable outcomes when the school's culture embraces and values professional learning. School cultures promoting professional learning are characterised by a supportive school leadership, trust between leadership and teachers, and opportunities for teachers to engage in structured dialogue and reflection about equity, which can empower teachers to enact transformative change (Jacobs et al., 2014). In less supportive school communities, establishing these conditions is a prerequisite to engaging in dialogue about equity. Without a supportive school culture, dialogue may be more likely to focus on stabilising existing narratives that reinforce structures of oppression, which can have a chilling effect on attempts to adopt more expansive and equitable views (Yoon, 2016).

Several high WoE studies suggest that teacher-leaders seeking to facilitate context-driven professional development work align their programs with the needs of the school or district to maximise the benefit to the populations they hope to serve. A programme should be contextualised to the particular school (Hynds \& McDonald, 2010; mid WoE), and programme goals should prioritise 'contribution to society' and 'enhancing quality of life' over standards and accountability (Ezzani, 2019, p. 8). Professional learning needs to align with the school and demography, and teachers should engage in a deeper examination of socioeconomic issues to achieve meaningful learning and to avoid reifying existing oppressive structures (Bryan, 2011).

Hynds and McDonald's (2010) study explored teacher motivation to improve the learning experiences and academic achievement of Māori and Pasifika students. In addition to intrinsic and extrinsic motivators (such as salary, certifications, employment, and training), teachers' desire to promote socially just educational opportunities and their eagerness to enact pedagogical changes positively influenced students' academic outcomes. Potential obstacles to teachers' goal fulfilment included inconsistent support, theory-praxis gap, and pedagogical challenges. School leaders who form deeper relationships with faculty can overcome teachers' initial resistance to school change efforts (Ezzani, 2019). A relational approach also assists teachers in bridging temporary obstacles and accomplishing their program goals.

\section{Normalising inclusion and shared leadership}

The final theme highlights approaches to embedding cultures of educational equity while also considering issues and challenges. Five articles with high WoE addressed this theme.

Galloway and Ishimaru (2019) wrote about school principals who 'normalise and centre conversations around race/racism and inclusion/exclusion' and referred to normalising an equity framing of educational inequalities (p. 17). The principals also 'implemented practices and routines to spread leadership across the teams, increasing shared power and decision-making and allowing for multiple perspectives' (p. 15). In a study that drew on Ishimaru and Galloway (2014), Park's (2018) work bridging organisational leadership and data-informed decision-making points to the role of informal leaders, and promotes normalising equity-focused conversation routines.

It is important to note that Park (2018) found that some common conversation moves (specifically confirming and disconfirming) 'can reinforce deficit assumptions about student abilities' (p. 642). Miled (2019) also identified practices and attitudes that were far from normalising inclusion and diversity: indeed participants denied the existence of racism in the district. While expressing moral commitment to multiculturalism they engaged in tokenistic approaches, either being unaware or 
unwilling to challenge systematic barriers that stood in the way of a critical transformation. Miled's study, involving not only school-based leaders but also district leaders and academics, proposed greater collaboration among leaders across different levels as part of the necessary response.

In a three-year study of an urban school with many challenges Reed and Swaminathan (2016) explored the distributed leadership, professional learning communities and social justice leadership approaches used by the principal that led to improved student achievement and school climate. Involving staff at all levels and sharing leadership were normal practices throughout this integrated approach. Kohli's (2019) recommendation for teacher education was to apply a sense of collectivism, as bringing teachers together supports their professional growth, enabling them to challenge inequalities.

Two articles with mid WoE surface resistance to professional development that would help normalise inclusion and shared leadership. Nehring and Fitzsimmons (2011) argue that teachers habitually participating in PLCs for professional development (rather than viewing them as optional) would assist systemic change. Payne and Smith (2018) found that leaders' resistance to LGBTQ-focused professional development formed a particular barrier to normalising inclusion since school leaders are gatekeepers to change.

\section{Normalising inclusion and shared leadership in teacher-focused literature}

Ezzani (2019) stresses a 'shift in leadership distribution' that involved teachers and school leaders collaborating in PLC meetings as a means to build solidarity among school faculty and to foster a culture of equity for students and teachers alike (p. 5). Such steps can lead to goal setting across grade levels, differentiating instruction to address student needs, and prioritising the needs of students within professional development contexts. According to Jacobs and colleagues (2014; high WoE), part of this 're-culturing process' (p. 579) involves teacher leaders moving beyond individual classrooms to ensure students have opportunities to achieve successful outcomes. The authors acknowledge the difficulty of balancing these goals against schools' current standards-based accountability requirements.

The teacher-focused literature envisions a re-cultured, inclusive school environment that culminates in inclusive and equitable experiences shared by students as well as teachers. Within the context of early childhood education, Nicholson and Kroll (2015) note that communities of professional learning in which administrators and teacher leaders collaborate can promote cultures of learning in schools that both inform instructional approaches and ensure more equitable outcomes for students. Yoon (2016) demonstrates the value of school leaders structuring professional learning groups so that equity remains the focus of dialogue.

\section{Discussion}

This review of research was conceived to reveal contemporary knowledge about leadership for professional learning that included a specific focus on promoting educational equity. Through the search, selection and analysis processes detailed above, studies were identified that addressed the guiding questions about leadership models, practices, and challenges relating to professional learning towards educational equity. In this section we critique the field of research, summarise what has been learned from the studies, challenge the hegemonic model of 'leaders' actions $\rightarrow$ teacher development $\rightarrow$ student outcomes', propose an alternative principled approach illustrated by a visual diagram to guide decision-making and practice in the field, and suggest further 
developments and implications. First though, an acknowledgement of limitations.

\section{Limitations}

All reviews of literature are partial (Hammersley, 2001), delimited by multiple parameters including search terms and sources as made explicit above; moreover, the interpretation of research is influenced by the perspectives of the authors (and readers). When synthesising the literature, it is impossible to do full justice to each item or to the body of work. These limitations are common to all such endeavours, hence the transparency of our process and positions included earlier. Reviews are also limited by the state of the field being studied.

\section{The field}

Research specifically addressing leadership for professional learning towards educational equity is a rigorous but very small field, located within the huge territory that encompasses all aspects of the three constituent parts as well as their connections. The field's knowledge base to date has been developed predominantly from US qualitative studies of small-scale interventions. Notable by their under-representation or near absence are studies from other countries, the use of quantitative and to a lesser extent mixed-methods approaches, and the student perspective. There is little evidence of causal relationships between leadership for professional learning and the actual achievement of more equitable outcomes for under-served and marginalised student groups. Rather, research to date offers more in terms of expanding and deepening knowledge about leadership for professional learning with the intention of enhancing educational equity, and about inhibiting factors. Race and ethnicity are a focus for much of this work, with little if any attention to other dimensions of difference associated with educational inequity (for example sex and gender, learning needs and disabilities, socioeconomics).

\section{Models, practices, and challenges}

In this section we summarise and discuss findings addressing the three research questions that related to models, practices, and challenges of leadership for professional learning towards equity.

The conceptual framework for professional learning presented above is based on models by Coldwell and Simkins (2011) and Hallinger (2018), and elaborated through contributions from four other conceptual and review articles. The figure and explanatory text include antecedents, contextual moderating factors, outcomes, and feedback relationships, all relevant to leadership. The framework is a theoretical model with the potential to inform policy and practice, increasing the likelihood of enhancing teacher knowledge and practice such that more equitable student outcomes are achieved. Further details about leadership and professional learning practices and challenges complement the framework. These were arrived at through analysis of empirical articles and are now discussed with reference to the five analytical themes.

In their conceptual discussion of framing, Braaten and colleagues (2017) cite Goffman (1974), Schon and Rein (1994), and Weick (1995) to emphasise the sensemaking processes of naming and prioritising that are behind the presentation of situations and the decisions about actions to be taken. Empirical studies in this review provided examples of school leaders deliberately and habitually framing issues in terms of equity (e.g., Galloway and Ishimaru, 2019), and of educators at all levels scrutinising social justice issues during professional learning activities (e.g., Jacobs et al., 2014). 
Critical reflection and explicit discussion that develop leaders' and teachers' capacity to make schools more equitable are key ways to address educators' lack of awareness about students' experiences and issues of inequity and to counter ingrained deficit-based orientations. Another challenge to educational equity is that recent accountability measures, particularly in the US and England, have severely narrowed what is most officially valued in students' learning to the easily testable aspects of a few core subjects. In this review, it is the work of Braaten and colleagues (2017) that explicitly addresses the framing of school improvement efforts and argues for 'expansive definitions of equity... [and to focus on] qualities of daily learning experiences' (p. 429). The thinking and communication inherent to the framing of social justice issues rest on dialogue and enquiry.

The close etymological connection between the two words 'dialogue' (stemming from the Greek for conversation and meaning 'through speech and reason') and 'enquiry' (from the Latin 'to ask a question') is mirrored in the practice of collaborative knowledge development. In such desired practices, school leaders, teachers and researchers ask questions of themselves and each other, about issues and situations, interrogating many forms of data. They talk respectfully in a collaborative search for understanding a shared focus, in both informal unplanned exchanges and in purposefully structured meetings. Such features were identified in studies included in this review, echoing in many ways reasoning that goes back to Dewey's (1933) reflective thinking grounded in investigation, and are central to the contemporary approaches of action research (Carr \& Kemmis, 1986; Pring, 2000) and lesson study (Dudley, 2015).

Reflective dialogic enquiry stimulates learning, and when purposefully framed has the potential to develop educators' identity towards educational equity. The careerlong evolution of school leaders' and teachers' professional identities can be associated with Huberman's (1993) classic stages of teachers' lives. However, rather than accepting a pre-determined natural order, the findings of studies in this review (e.g., Kose, 2009; Deckman, 2017) endorse engineering early and sustained professional learning so as to strengthen teachers' identity development as champions of social justice.

'Context' encompasses many factors that influence the leadership of professional learning towards educational equity. Internal school cultures may be more or less supportive of professional learning particularly when it challenges the status quo (Jacobs et al., 2014). The multiple complexities of external contexts require critical, creative, empowering and sustained leadership responses characterised by informed, reflective decision-making, as illustrated in Reed and Swaminathan's (2016) case study. Accompanying the very many relevant socio-economic and cultural influences are aspects of the political context, notably high-stakes test-based accountability systems. These have become deeply established yet have wide-ranging pernicious consequences (Darling-Hammond, 2004; Mansell, 2007) including educational disadvantage for minority students as discussed by studies in this review (e.g., Galloway \& Ishimaru, 2019; Ashardi \& Rice, 2016; Anthony \& Hunter; 2017; Carpenter et al., 2017). To temper these and other challenges for social justice, educators have their own and colleagues' equity-orientated motivations, as well as other resources. Research provides valuable knowledge, approaches and programmes to address disadvantage, though these must be approached critically and with regard to specific situations. Arguably the most valuable resources of all are the students themselves, their families and communities yet, as Mansfield (2014) and Hajisoteriou and colleagues (2018) indicate, they are often neglected or overlooked. 
Involving students fully in all aspects of their education, including through student leadership, has the potential to transform education (Cook-Sather, 2010; Hill, 2019). Normalising inclusion and shared leadership in all forms are both desired outcomes and necessary on-going processes of socially-just education. While the items in this review provide examples of positive approaches (e.g., Ezzani, 2019; Nicholson \& Kroll, 2015), there was also evidence of substantial challenges (Miled, 2019; Nehring $\&$ Fitzsimmons, 2011). Much rests on, and must be addressed through, school and organisational cultures. Normalising inclusion and shared leadership will always be work in progress, requiring continued activity and critical attention.

\section{An alternative principled approach}

Thus far, we have synthesised recent conceptual and review articles to present a revised framework, and analysed empirical articles with a focus on educational equity to generate knowledge about leadership for professional learning practices. The model presented in Figure 1 elaborates the hegemonic input-output model, providing additional knowledge and guidance. This and similar 'pathway' models are well grounded in research and literature, appear rational, and have a strong hold internationally. However, as Boylan and colleagues (2018) point out, all models are partial, and could be considered as 'tools to be deployed' (p. 138). While we hope the elaborated model developed through this review is useful, our fundamental unease with the linear model prompted an alternative approach as discussed below.

Half a century ago Lawrence Stenhouse was troubled by the gaps he observed between teachers' plans and what occurred in practice. This led him to develop a process model of education, valuing teachers' and students' learning as the growth of understanding through critical enquiry, and a broad conception of outcomes that included knowledge not as facts to be memorised but as 'facts so structured by theory that they acquire meaning' (Stenhouse, 1975, p. 17). Stenhouse was influenced by philosophical, sociological, and psychological sources not only from the UK but also the US and Scandinavia (James, 2012). He emphasised key elements of his thinking in a summary sentence: 'A curriculum is an attempt to communicate the essential principles and features of an educational proposal in such a form that it is open to critical scrutiny and capable of effective translation into practice' (Stenhouse, 1975, p. 4).

The notion of principles of procedure (derived from Peters, 1959) has been applied to other educational endeavours, including Leadership for Learning (MacBeath \& Dempster, 2009; MacBeath et al., 2018), Assessment for Learning (Klenowski, 2009; Swaffield, 2011; Swaffield et al., 2016), and to summarise the findings from a ten-year Teaching and Learning Research Programme of many projects across the UK involving learners of all ages and in different contexts (James \& Pollard, 2011). These precedents, and the value stances that can be traced from Stenhouse's work, led us to conceive of the identified themes in our review in terms of principles for the leadership of professional learning towards educational equity.

We illustrate these nascent principles and the relationships among them in Figure 4 below. Firstly, the five principles are presented within a circular diagram to suggest that the relationship among them is cyclical and ongoing, rather than linear with beginning and end points. Secondly, the dotted lines around and between the principles indicate that permeable boundaries as each of the principles are interrelated and meld into one another. Finally, we have organised the principles to orient the reader to our current understanding of their interrelationships. 'Critical framing of issues toward social justice' is fundamental to the other principles and is thus situated at the centre of the diagram, with the other principles - 'Dialogue and enquiry', 'Learning and identity 
development', and 'Normalising inclusion and shared leadership' - orbiting around it. These are seen both as activities intentionally undertaken toward social justice and educational equity, and as the results of that intentionality. The remaining principle is presented as the largest of the concentric circles because it forms the circumstances that the principles are influenced and moderated by: 'Context, resources, and motivations'.

Figure 4. Nascent principles of leadership for professional learning towards educational equity.

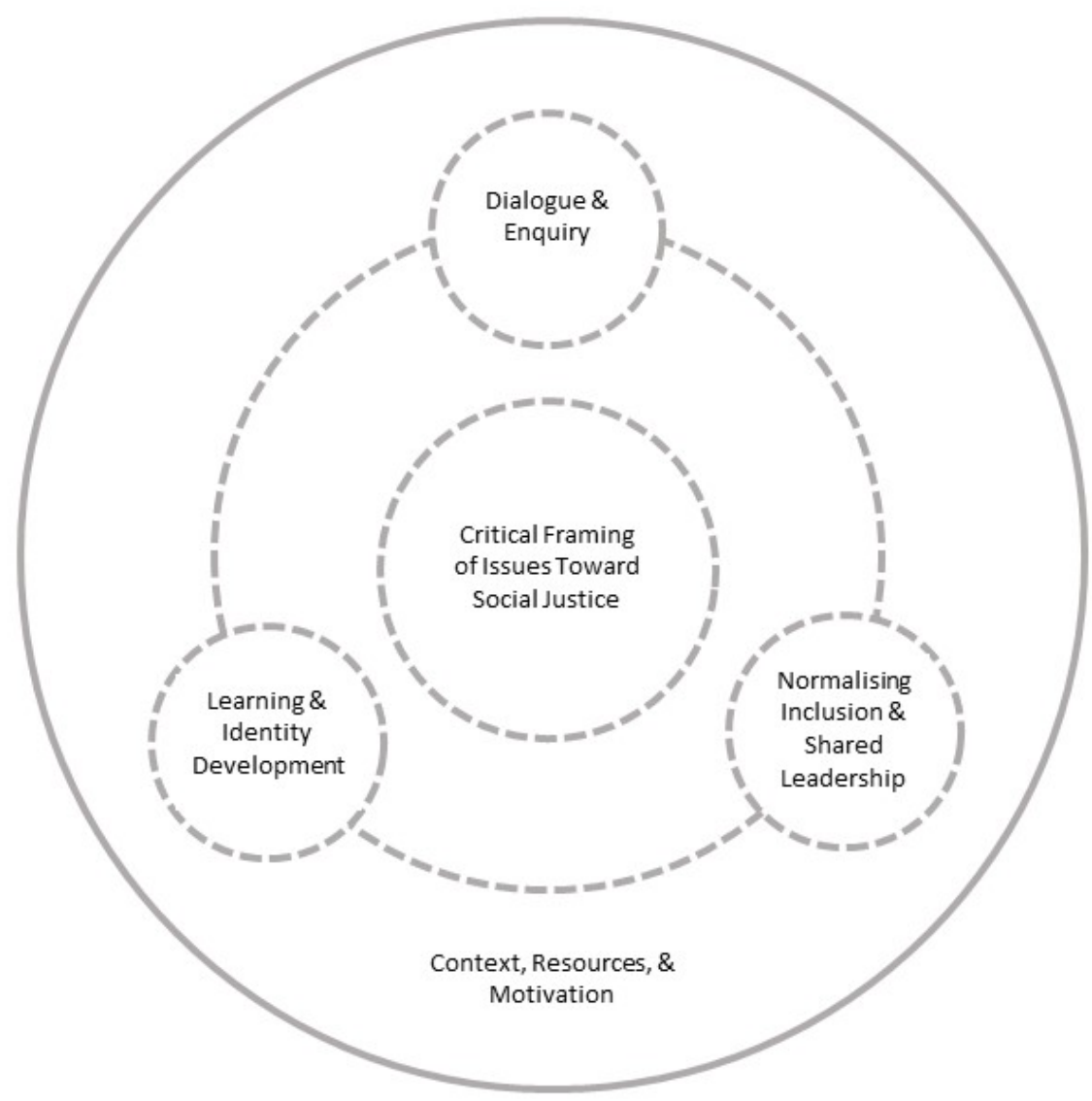

\section{Implications and future development}

The suggested principles need to be tried and tested in practice, exploring their applicability to different contexts, and their utility for guidance and formative evaluation. Their conceptualisation requires further work. There is huge potential to expand the knowledge base of leadership for professional learning toward educational equity, adding to the empirical studies included in this review, particularly with a greater variety of research approaches. Most pressing of all is the inclusion of students, especially from marginalised groups, as equal collaborators in dialogue and enquiry to develop the field further. 


\section{Conclusion}

While acknowledging limitations and trusting it will be read with these in mind, we suggest that this study's significance is four-fold.

Firstly, it addresses Hallinger and Kulophas' (2020, p 14) 'high priority recommendation' for reviews of research that explicitly target leadership and teacher learning, while focusing on research also concerned with social justice.

Secondly, it elaborates the common, linear model of professional development activities leading to teacher learning, and thus to the final outcome of student learning, particularly with additional moderating factors, lines of influence and feedback, and contexts.

Thirdly, it summarises (some of) what is known about leadership for professional learning towards educational equity and acts as a resource for researchers, policymakers, and practitioners.

Finally, it proposes five nascent principles, supported by an aide memoire illustration, that can be used to plan, guide, and evaluate leadership for professional learning toward educational equity. Leaders and teachers can use the principles as mental tools to inform their in-the-moment decisions, shaping their speech and actions to make education more socially just. We are already beginning to use and further develop this alternative principled approach, and hope that others will join the endeavour, with the ultimate aim of serving all learners more equitably.

As a last but important note, this paper was finalised as racial justice protests erupted across the world in the wake of the unjust killings of numerous Black people, including George Floyd, which underscores the urgency toward achieving this goal.

\section{Acknowledgements}

The authors would like to thank the journal's anonymous reviewers and editor for their feedback, as well as Anna Vignoles, Thomasenia Adams, and David Lawrence Jr. for their comments on previous versions of this paper.

\section{References}

Ali, T. (2014). Development of teacher leadership: A multi-faceted approach to bringing about improvements in rural elementary schools in Pakistan. Professional development in education, 40(3), 352-375. https://doi.org/10.1080/19415257.2013.828238

Anthony, G., \& Hunter, R. (2017). Grouping practices in New Zealand mathematics classrooms: Where are we at and where should we be? New Zealand journal of educational studies, 52(1), 73-92. https://doi.org/10.1007/s40841-016-0054-z

Ashadi, A., \& Rice, S. (2016). High stakes testing and teacher access to professional opportunities: Lessons from Indonesia. Journal of education policy, 31(6), 727741. https://doi.org/10.1080/02680939.2016.1193901

Blank, M. J. (2015). Building sustainable health and education partnerships: Stories from local communities. Journal of school health, 85(11, SI), 810-816. https://doi.org/10.1111/josh.12311

Boylan, M., Coldwell, M., Maxwell, B., \& Jordan, J. (2018). Rethinking models of professional learning as tools: A conceptual analysis to inform research and practice. Professional development in education, 44(1), 120-139. DOI: 10.1080/19415257.2017.1306789

Braaten, M., Bradford, C., Kirchgasler, K. L., \& Barocas, S. F. (2017). How data use for accountability undermines equitable science education. Journal of educational administration, 55(4), 427-446. https://doi.org/10.1108/JEA-09-2016-0099 
Brinia, V., 2012. Men vs women; educational leadership in primary schools in Greece: an empirical study. International journal of educational management, 26(2), 175-191. doi: 10.1108/09513541211201988.

Bristol, L. (2015). Leading-for-inclusion: Transforming action through teacher talk. International journal of inclusive education, 19(8), 802-820. https://doi.org/10.1080/13603116.2014.971078

Bristol, L., \& Ponte, P. (2013). 'Muddying the space': Social justice, action research and professional learning. Professional development in education, 39(4), 513530. https://doi.org/10.1080/19415257.2013.797007

Brown, J. C., \& Crippen, K. J. (2017). The knowledge and practices of high school science teachers in pursuit of cultural responsiveness. Science education, 101(1), 99-133. https://doi.org/10.1002/sce.21250

Brunton, G., Stansfield, C., \& Thomas, J. (2012). Finding relevant studies. In: Gough, D., Oliver, S., \& Thomas, J. eds.. An introduction to systematic reviews. Thousand Oaks, CA: Sage, 107-134.

Bryan, C. (2011). Professional development during a period of change: A small-scale case study exploring the effect of context on practice in a South African rural school. Professional development in education, 37(1), 131-141. https://doi.org/10.1080/19415257.2010.499302

Carpenter, B. W., Bukoski, B. E., Berry, M., \& Mitchell, A. M. (2017). Examining the social justice identity of assistant principals in persistently low-achieving schools. Urban education, 52(3), 287-315. https://doi.org/10.1177/0042085915574529

Carr, W. \& Kemmis, S. (1986). Becoming critical: Knowing through action research. London: Falmer.

Castanheira, P. S. P. (2016). Mentoring for educators' professional learning and development: A meta-synthesis of IJMCE volumes 1-4. International journal of mentoring and coaching in education, 5(4), 334-346. https://doi.org/10.1108/IJMCE-10-2015-0030

Cochran-Smith, M. and Lytle, S., 2009. Inquiry as stance: Practitioner research for the next generation (Practitioner inquiry series). New York: Teachers College.

Coldwell, M., \& Simkins, T. (2011). Level models of continuing professional development evaluation: A grounded review and critique. Professional development in education, 37(1), 143-157. https://doi.org/10.1080/19415257.2010.495497

Cook-Sather, A. (2010). Students as learners and teachers: Taking responsibility, transforming education, and redefining accountability. Curriculum inquiry, 40(4)), 555-575.

Cruz-González, C., Domingo Segovia, J., \& Lucena Rodriguez, C. (2019). School principals and leadership identity: A thematic exploration of the literature. Educational research, 61(3), 319-336. https://doi.org/10.1080/00131881.2019.1633941

Darling-Hammond. L. (2004) Standards, accountability and school reform. Teachers College record, 106(6), 1047-1085.

Darling-Hammond, L., Wei, R. C., Andree, A., Richardson, N., \& Orphanos, S. (2009). Professional learning in the learning profession: A status report on teacher development in the U.S. and abroad. (p. 36). National Staff Development Council. https://edpolicy.stanford.edu/sites/default/files/publications/ professional-learning-learning-profession-status-report-teacher-development-usand-abroad.pdf 
Deckman, S. L. (2017). Managing race and race-ing management: Teachers' stories of race and classroom conflict. Teachers College record, 119(11), 1-40.

DeMatthews, D., \& Izquierdo, E. (2016). School leadership for dual language education: A social justice approach. Educational forum, 80(3), 278-293. https://doi.org/10.1080/00131725.2016.1173152

Desimone, L. M., Porter, A. C., Garet, M. S., Yoon, K. S., \& Birman, B. F. (2002). Effects of professional development on teachers' instruction: Results from a three-year longitudinal study. Educational evaluation and policy analysis, 24(2), 81-112. https://doi.org/10.3102/01623737024002081

Dewey, J. (1933). How we think: A restatement of the relation of reflective thinking to the educative process. Chicago: Henry Regnery.

Dudley, P. (Ed.) (2015). Lesson study: Professional learning for our time. Abingdon: Routledge.

Ezzani, M. D. (2019). Principal and teacher instructional leadership: A cultural shift. International journal of educational management. https://doi.org/10.1108/IJEM02-2019-0071

Fry, G. W., \& Bi, H. (2013). The evolution of educational reform in Thailand: The Thai educational paradox. Journal of educational administration, 51(3), 290-319. https://doi.org/10.1108/09578231311311483

Fwu, B., \& Wang, H. (2012). Bridging the gap between and beyond school science through collaboration: Promoting science teachers' professional development through diversity and equal partnership. Asia-Pacific educational researcher, 21(3), 464-473.

Galloway, M. K., \& Ishimaru, A. M. (2019). Leading equity teams: The role of formal leaders in building organizational capacity for equity. Journal of education for students placed at risk. https://doi.org/10.1080/10824669.2019.1699413

Gannon-Slater, N., La Londe, P. G., Crenshaw, H. L., Evans, M. E., Greene, J. C., \& Schwandt, T. A. (2017). Advancing equity in accountability and organizational cultures of data use. Journal of educational administration, 55(4), 361-375. https://doi.org/10.1108/JEA-09-2016-0108

García-Martínez, I., \& Tadeu, P. (2018). The influence of pedagogical leadership on the construction of professional identity. Systematic review. Journal of social studies education research, 9(3), 145-162. https://doi.org/10.17499/jsser.90982

Goffman, E., 1974. Frame Analysis: An essay on the organization of experience, Cambridge, MA: Harvard Educational Press.

Gomez-Hurtado, I., Gonzalez-Falcon, I., \& Coronel, J. M. (2018). Perceptions of secondary school principals on management of cultural diversity in Spain. The challenge of educational leadership. Educational management administration \& leadership, 46(3), 441-456. https://doi.org/10.1177/1741143216670651

Gough, D. (2007). Weight of Evidence: A framework for the appraisal of the quality and relevance of evidence. Research papers in education, 22(2), 213-228. https://doi.org/10.1080/02671520701296189

Hajisoteriou, C., Karousiou, C., \& Angelides, P. (2018). Successful components of school improvement in culturally diverse schools. School effectiveness and school improvement, 29(1), 91-112. https://doi.org/10.1080/09243453.2017.1385490

Hallinger, P. (2018). Bringing context out of the shadows of leadership. Educational management administration \& leadership, 46(1), 5-24. https://doi.org/10.1177/1741143216670652 
Hallinger, P., \& Kulophas, D. (2020). The evolving knowledge base on leadership and teacher professional learning: A bibliometric analysis of the literature, 19602018. Professional development in education, 46(4), 1-20. https://doi.org/10.1080/19415257.2019.1623287

Hallinger, P. \& Liu, S., 2016. Leadership and teacher learning in urban and rural schools in China: meeting the dual challenges of equity and effectiveness. International journal of educational development, 51, 163-173. doi: 10.1016/j.ijedudev.2016.10.001.

Hammersley, M. (2001). On 'systematic' reviews of research literatures: A 'narrative' response to Evans \& Benefield. British educational research journal, 27(5), 543-554.

Hardy, I. J. (2010). Teacher talk: Flexible delivery and academics' praxis in an Australian university. International journal for academic development, 15(2), 131-142. https://doi.org/10.1080/13601441003738277

Hill, S. (2019). Softening the hierarchy: the role of student agency in building learning organisations. Journal of professional capital and community, 4(2), 147-162.

Huberman, M. (1993) The lives of teachers. London: Cassell.

Hynds, A. (2010). Unpacking resistance to change within-school reform programmes with a social justice orientation. International journal of leadership in education, 13(4), 377-392. https://doi.org/10.1080/13603124.2010.503282

Hynds, Anne, \& McDonald, L. (2010). Motivating teachers to improve learning for culturally diverse students in New Zealand: Promoting Māori and Pacific Islands student achievement. Professional development in education, 36(3), 525-540. https://doi.org/10.1080/19415250903319275

Ishimaru, A. M., \& Galloway, M. K. (2014). Beyond individual effectiveness: Conceptualizing organizational leadership for equity. Leadership and policy in schools, 13(1), 93-146. https://doi.org/10.1080/15700763.2014.890733

Jacobs, J., Beck, B., \& Crowell, L. (2014). Teacher leaders as equity-centered change agents: Exploring the conditions that influence navigating change to promote educational equity. Professional development in education, 40(4), 576-596. https://doi.org/10.1080/19415257.2014.896272

James, M. \& Pollard, A. (2011) TLRP's ten principles for effective pedagogy: Rationale, development, evidence, argument and impact. Research papers in education, 26(3), 275-328.

James, M. (2012) An alternative to the objectives model: the process model for the design and development of curriculum. In: N. Norris \& J. Elliott, eds.. Curriculum, pedagogy and educational research: The work of Lawrence Stenhouse. Abingdon: Routledge: 61-83.

Klenowski, V. (2009). Assessment for learning revisited: an Asia-Pacific perspective. Assessment in education: principles, policy \& practice, 16(3), 263- 268.

Kohli, R. (2019). Lessons for teacher education: The role of critical professional development in teacher of color retention. Journal of teacher education, 70(1), 39-50. https://doi.org/10.1177/0022487118767645

Kose, B. W. (2009). The principal's role in professional development for social justice: An empirically based transformative framework. Urban education, 44(6), 628663. https://doi.org/10.1177/0042085908322707

Ladson-Billings, G. (2006). From the achievement gap to the education debt: Understanding achievement in U.S. schools. Educational researcher, 35(7), 312. https://doi.org/10.3102/0013189X035007003 
Lazar, A.M. \& Reich, L.M., 2016. What school leaders and teacher mentors can do to support teachers for social equity. In: A.M. Lazar \& L.M. Reich, eds.. New teachers in urban schools: journeys toward social equity teaching. Cham: Springer, 121-139. doi:10.1007/978-3-319-26615-2_8.

Lee, M., \& Hallinger, P. (2012). National contexts influencing principals' time use and allocation: Economic development, societal culture, and educational system. School effectiveness and school improvement, 23(4), 461-482. https://doi.org/10.1080/09243453.2012.678862

MacBeath, J. \& Dempster, N. (Eds.) (2009). Connecting leadership and learning: Principles for practice. London: Routledge.

MacBeath, J., Dempster, N., Frost, D., Johnson, G. \& Swaffield, S. (2018). Strengthening the connections between leadership and learning. Abingdon: Routledge.

Mansell, W. (2007). Education by numbers: The tyranny of testing. London: Portico's Publishing.

Mansfield, K. C. (2014). How listening to student voices informs and strengthens social justice research and practice. Educational administration quarterly, 50(3), 392430. https://doi.org/10.1177/0013161X13505288

Martinez, M. A., Rivera, M. \& Marquez, J., 2019. Learning from the experiences and development of Latina school leaders. Educational administration quarterly. 119. doi: 10.1177/0013161X19866491.

Miled, N. (2019). Educational leaders' perceptions of multicultural education in teachers' professional development: A case study from a Canadian school district. Multicultural education review, 11(2), 79-95. https://doi.org/10.1080/2005615X.2019.1615249

Mistry, M., \& Sood, K. (2015). Permeating the social justice ideals of equality and equity within the context of early years: Challenges for leadership in multicultural and mono-cultural primary schools. Education 3-13, 43(5), 548-564. https://doi.org/10.1080/03004279.2013.837944

Moher, D., Liberati, A., Tetzlaff, J., Altman, D. G., \& Group, T. P. (2009). Preferred reporting items for systematic reviews and meta-analyses: The PRISMA statement. PLOS medicine, 6(7), 1-6. https://doi.org/10.1371/journal.pmed.1000097

Murakami, E. T. \& Törnsen, M., 2017. Female secondary school principals: Equity in the development of professional identities. Educational management administration and leadership, 45 (5, SI), 806-824. doi: $10.1177 / 1741143217717273$.

Nehring, J., \& Fitzsimons, G. (2011). The professional learning community as subversive activity: Countering the culture of conventional schooling. Professional development in education, 37(4), 513-535. https://doi.org/10.1080/19415257.2010.536072

Nicholson, J. M., \& Kroll, L. (2015). Developing leadership for early childhood professionals through oral inquiry: Strengthening equity through making particulars visible in dilemmas of practice. Early child development and care, 185(1), 17-43. https://doi.org/10.1080/03004430.2014.903939

Opfer, V. D. \& Pedder, D., 2011. Conceptualizing teacher professional learning. Review of educational research, 81(3), 376-407. doi: 10.3102/0034654311413609.

Park, V. (2018). Leading data conversation moves: Toward data-informed leadership for equity and learning. Educational administration quarterly, 54(4), 617-647. https://doi.org/10.1177/0013161X18769050 
Patton, L. D., \& Bondi, S. (2015). Nice white men or social justice allies? Using critical race theory to examine how white male faculty and administrators engage in ally work. Race ethnicity and education, 18(4), 488-514. https://doi.org/10.1080/13613324.2014.1000289

Payne, E. C., \& Smith, M. J. (2018). Refusing relevance: School administrator resistance to offering professional development addressing LGBTQ issues in schools. Educational administration quarterly, 54(2), 183-215. https://doi.org/10.1177/0013161X17723426

Peters, R. S. (1959). Authority, responsibility and education. London: Allen \& Unwin.

Pfeffer, J., \& Sutton, R. I. (2000). The knowing-doing gap: How smart companies turn knowledge into action. Harvard Business School Press. https://books.google.se/books?id=MeY5hdgj1bAC. Accessed 27 May 2020.

Pring, R. (2000). Philosophy of educational research. London: Continuum.

Reed, L. C., \& Swaminathan, R. (2016). An urban school leader's approach to school improvement: Toward contextually responsive leadership. Urban education, 51(9), 1096-1125. https://doi.org/10.1177/0042085914553675

Scanlan, M. (2010). Slogging and stumbling toward social justice in a private elementary school: The complicated case of St. Malachy. Education and urban society, 42(5), 572-598. https://doi.org/10.1177/0013124510366224

Schleicher, A. (2019). PISA 2018: Insights and interpretations. Paris, France: Organization for economic cooperation and development. Available at https://www.oecd.org/pisa/PISA\%202018\%20Insights\%20and\%20Interpretation s\%20FINAL\%20PDF.pdf. Accessed 25 May 2020.

Schön, D.A. \& Rein, M., 1994. Frame reflection. New York: Basic Books.

Stenhouse, L. (1975). An introduction to curriculum research and development. London: Heinemann.

Stosich, E. L., 2017. Leading in a time of ambitious reform: principals in high-poverty urban elementary schools frame the challenge of the common core state standards. Elementary school journal, 117 (4), 539-565. doi: 10.1086/691585.

Sun, J. (2015). Conceptualizing the critical path linked by teacher commitment. Journal of educational administration, 53(5), 597-624. https://doi.org/10.1108/JEA-052013-0063

Swaffield, S. (2011) Getting to the heart of authentic assessment for learning. Assessment in education: Principles, policy and practice, 18(4), 433-449.

Swaffield, S., Rawi, R. \& O'Shea, A. (2016). Developing assessment for learning practice in a school cluster: Primary and secondary teachers learning together. In: D. Laveault \& L. Allal, eds.. Assessment for learning: Meeting the challenge of implementation. Rotterdam: Springer: 119-217. DOI 10.1007/9783-319-39211-0_12

Szelei, N., Tinoca, L., \& Pinho, A. S. (2019). Professional development for cultural diversity: The challenges of teacher learning in context. Professional development in education, 1-17. https://doi.org/10.1080/19415257.2019.1642233

Theoharis, G., \& O'Toole, J. (2011). Leading inclusive ELL: Social justice leadership for English Language Learners. Educational administration quarterly, 47(4), 646-688. https://doi.org/10.1177/0013161X11401616

Weick, K., 1995. Sensemaking in organizations, Thousand Oaks, CA: Sage.

Welch, V., Petticrew, M., Tugwell, P., Moher, D., O'Neill, J., Waters, E., et al., (2012) PRISMA-Equity 2012 Extension: Reporting Guidelines for Systematic Reviews 
with a Focus on Health Equity, PLoS medicine 9(10): e1001333.

doi:10.1371/journal.pmed.1001333

Yoon, I. H. (2016). Trading stories: Middle-class white women teachers and the creation of collective narratives about students and families in a diverse elementary school. Teachers College record, 118(2), 1-54. 